\title{
Conventional ultrasound, color Doppler, TI- RADS, and shear wave elastography for thyroid nodule differentiation: a study of efficacy compared with the histopathology results
}

\author{
Ahmed Abd Alrahman Baz ${ }^{1 *}$, Afaf Hamdy Ibrahim Mohamed', Yasmine Fathy Ghazi El-Esawy ${ }^{2}$ and \\ Khaled Helmy El-kaffas ${ }^{1}$
}

\begin{abstract}
Background: Although a minority of the thyroid nodules is malignant, usually the invasive diagnostic procedures are warranted. This prospective study aims to assess the diagnostic performance of the US criteria in addition to the TI-RADS score and the SWE for the differentiation between the benign and malignant thyroid nodules as a potential surrogate for the invasive procedures.

Results: Ninety-nine patients with thyroid nodules (79 females and 20 males, with a mean age of $45.9 \pm 7.7$ years; 30-69 years) were enrolled in this study and underwent conventional ultrasound, color Doppler, TI-RADS scoring, and shear wave elastography (SWE); the findings were correlated to the histopathological results.

Our results revealed a significant increase in SWE elasticity indices (Els) and presence of color Doppler signals in malignant nodules as compared with the benign ones $(\rho<0.05)$. Combined TI-RADS and SWE as well as TI-RADS and color Doppler imaging had given a better sensitivity for detection of malignancy.

Conclusion: Elasticity indices had shown a significantly high diagnostic performance that is almost approaching the histopathological results. Combined SWE, color Doppler and TI-RADS, as a sum of findings, could effectively differentiate between benign and malignant thyroid nodules. Furthermore, it had offered a non-invasive tool for accurate risk stratification of malignant nodules.
\end{abstract}

Keywords: Thyroid Nodules, Ultrasound, Shear wave elastography, Fine needle aspiration

\section{Background}

Thyroid nodules are commonly encountered clinical and radiological findings in the clinical practice; however, only minorities (less than $5 \%$ ) of them are truly malignant and need further evaluation [1-5].

In the past, the assessment of the thyroid nodules used to be done by clinical examination, ultrasound, and

\footnotetext{
*Correspondence: ahmedbaz2012@yahoo.com

${ }^{1}$ Radiology Department, Faculty of Medicine, Cairo University, Cairo, Egypt

Full list of author information is available at the end of the article
}

radioisotopic scanning. Nonetheless, the cytological assessment by either fine-needle aspiration cytology (FNAC) or biopsy is often needed to preclude malignancy [3, 4].

The clinical examination per se cannot give a final diagnosis and usually, the US examination is requested; thus, some ultrasound criteria were employed for categorization of the suspicious nodules. A scoring system known as thyroid imaging reporting and data system (TI-RADS) has been validated, widely used, and updated in this regard $[3,5,6]$.
Springer Open

(c) The Author(s). 2021 Open Access This article is licensed under a Creative Commons Attribution 4.0 International License, which permits use, sharing, adaptation, distribution and reproduction in any medium or format, as long as you give appropriate credit to the original author(s) and the source, provide a link to the Creative Commons licence, and indicate if changes were made. The images or other third party material in this article are included in the article's Creative Commons licence, unless indicated otherwise in a credit line to the material. If material is not included in the article's Creative Commons licence and your intended use is not permitted by statutory regulation or exceeds the permitted use, you will need to obtain permission directly from the copyright holder. To view a copy of this licence, visit http://creativecommons.org/licenses/by/4.0/. 
Elastography has been added as an ultrasound-based technique including the strain and the shear wave elastography (SWE) for getting an objective assessment of the tissue stiffness in organs like the liver and the breast lesions; nevertheless; the diagnostic accuracy of the thyroid elastography in malignancy detection is still controversial in the literature $[5,6]$.

Recently, functional imaging like diffusion-weighted MRI (DW-MRI) has been investigated for assessing thyroid malignancies as well as their recurrences, and it had reported fairly good results, but MRI has some limitations being contraindicated in claustrophobic patients and those with cardiac pacemakers; moreover, it is more expensive compared with the US $[7,8]$.

Eventually, some studies had investigated the use of SWE as a potential surrogate for invasive procedures (like FNAC) in the evaluation of soft thyroid nodules [9].
This prospective study aims to assess the diagnostic performance of the US criteria in addition to the TIRADS score, and the SWE for differentiation between the benign and malignant thyroid nodules in patients referred for FNAC and to correlate the imaging patterns and the obtained values of the lesions with their histopathological results as a reference standard.

\section{Methods \\ Subjects}

This study had enrolled 99 patients with thyroid nodules who were referred to US or intervention units in our institute from the outpatient clinics, and the inpatient departments within the period from January 2019 to August 2020, there were 79 females and 20 males having a mean age of $45.92 \pm 7.7$ years $(30-69$ years).

Table 1 Showing the diagnostic performance of conventional B-mode and color Doppler characteristics of the nodules

\begin{tabular}{|c|c|c|c|c|c|}
\hline Us features & & Malignant & Benign & $\begin{array}{l}\text { Sensitivity (\%) or chi } \\
\text { squared, } t \text { value } \mathrm{a}^{\mathrm{a}}\end{array}$ & $\begin{array}{l}\text { Specificity (\%) or } \\
p \text { value }\end{array}$ \\
\hline Nodule size in $\mathrm{mm}$ & & $27.7 \pm 6.9$ & $\begin{array}{l}29.4 \pm \\
4.1\end{array}$ & $t=1.5$ & $p=0.125$ \\
\hline \multirow[t]{2}{*}{ Number of nodule } & Solitary nodule & 27 & 47 & Chi squared $=1.3$ & 0.252 \\
\hline & Multiple nodules ${ }^{a}$ & 6 & 19 & & \\
\hline \multicolumn{6}{|l|}{$\begin{array}{l}\text { Location of the } \\
\text { nodule }\end{array}$} \\
\hline & Right lobe & 11 & 22 & Chi squared $=0.060$ & $p$ value $=0.996$ \\
\hline & Left lobe & 17 & 33 & & \\
\hline & Isthmus & 3 & 7 & & \\
\hline & Different & 2 & 4 & & \\
\hline \multirow[t]{2}{*}{ Composition } & Solid $(n=75)$ & 30 & 45 & 90.9 & 31.8 \\
\hline & Partially solid $(n=24)$ & 3 & 21 & & \\
\hline \multirow[t]{2}{*}{ Echogenicity } & $\begin{array}{l}\text { Hypo or marked hypoechogenicity ( } n \\
=28 \text { ) }\end{array}$ & 22 & 6 & 66.6 & 90.9 \\
\hline & Hyper or isoechogenicity $(n=71)$ & 11 & 60 & & \\
\hline \multirow[t]{2}{*}{ Calcification } & Microcalcification $(n=12)$ & 12 & 0 & 36.3 & 10 \\
\hline & Macro or no calcification $(n=87)$ & 21 & 66 & & \\
\hline \multirow[t]{2}{*}{ Shape } & Taller than wider $(n=4)$ & 4 & 0 & 12.1 & 10 \\
\hline & Wider than taller $(n=95)$ & 29 & 66 & & \\
\hline \multirow[t]{2}{*}{ Margin } & Irregular/ lobulated $(n=13)$ & 2 & 11 & 6.06 & 83.3 \\
\hline & Smooth/ill-defined $(n=86)$ & 31 & 55 & & \\
\hline \multirow[t]{3}{*}{ TI-RADS } & $\operatorname{TR} 3(n=60)$ & 5 & 55 & 84.8 of TR4 as a cutoff value & 83.3 of TR4 as a cutoff value \\
\hline & TR4 $(n=37)$ & 26 & 11 & & \\
\hline & TR5 $(n=2)$ & 2 & 0 & & \\
\hline \multirow[t]{4}{*}{ Color Doppler } & Avascular $(0)(n=70)$ & 15 & 55 & \multirow{4}{*}{$\begin{array}{l}54.5 \text { of intra-nodular vascularity } \\
\text { as a cutoff value }\end{array}$} & \multirow{4}{*}{$\begin{array}{l}100 \text { of intra-nodular vascularity } \\
\text { as a cutoff value }\end{array}$} \\
\hline & Peri-nodular vascularity (1a) $(n=11)$ & 0 & 11 & & \\
\hline & Intra-nodular vascularity (1b) $(n=15)$ & 15 & 0 & & \\
\hline & Peri \& intra- vascularities (1c) $(n=3)$ & 3 & 0 & & \\
\hline
\end{tabular}

aln cases of multiple nodules, the target nodule was considered as the most suspicious one, based on the B-mode and the color Doppler findings in addition to the highest TI-RADS score. 
Table 2 Showing analysis of the elasticity indices of SWE

\begin{tabular}{llllllll}
\hline & Number & Mean & Median & Std deviation & Range & Minimum & Maximum \\
\hline$E_{\text {mean }}(\mathrm{kPa})$ & 99 & 40.1 & 26.9 & 29.2 & 113.9 & 9.1 & 123 \\
$\mathrm{ER}$ & 2.53 & 3.1 & 1.9 & 2.3 & 8 & 1.0 & 9.0
\end{tabular}

$E_{\text {mean: }}$ the mean elasticity index of the stiffest portion of the nodule, $E R$ the ratio of mean elasticity index of the lesion and parenchyma or surrounding sternocleidomastoid muscle

- Inclusion criteria: Patients with suspicious thyroid nodules (solid or partially solid; based on the clinical and US examinations) who were referred for FNCA

- Exclusion criteria: Patients with an abnormal bleeding profile or those who had only diffuse thyroid disease but no existing nodules, also those who had pure cystic nodules

This study was conducted following the ethical guidelines of the Research Ethics Committee of our institute (reference number: Code D-24-2019; date of approval 13-07-2019), and it was approved. All the participants were informed of the details and gave their written informed consent.

All of our patients were subjected to the following:

\section{Conventional ultrasound and shear wave elastography}

B-mode and color Doppler examinations were done traditionally for assessing the number, size, composition, echogenicity, shape, margin, and calcification of the nodules (Table 1). Then, the nodules were scored according to ACR TI-RADS criteria [10].

Vascularity-wise, the examined nodules were classified accordingly into avascular nodules (0), nodules with peripheral vascularity (1a), nodules with internal vascularity (1b), and nodules with both peripheral and internal vascularities (1c) (Table 1).

TOSHIBA Aplio 500 machine (equipped with a 7.5$\mathrm{MHz}$ linear probe) was used.

Shear wave examination was subsequently done by the same operator (who is a 3-year experienced subject with the US and elastography techniques) for target nodules using the same US machine and probe. After identification of the lesion, the transducer was kept in a stable perpendicular position without pressure for $3 \mathrm{~s}$ to minimize the compression artifact.

Shear wave mode was applied over the B-mode image. A color signal box of appropriate size was displayed as a colored area, where softer areas were blue, and the harder areas were red. Whenever the cine loop was stable by showing parallel lines or parallel circles (free of dot artifacts or zigzag lines), we froze the image and started the interrogation process.

Elastographic quantitative assessment was done using a suitable region of interest (ROI), that was placed in the stiffest region, but avoiding the cystic components, visible calcifications, and the surrounding blood vessels.

The average SWE values in the selected ROI were recorded in kilo Pascal $(\mathrm{kPa})$ for each lesion. A second ROI of the appropriate size was placed in the normal thyroid parenchyma or on the sternocleidomastoid muscle to obtain the elastic ratio (ER), which is the mean stiffness for the lesion-to-normal parenchyma. Repeating the process (at least three successive measurements) was performed for the nodule to choose the best SWE image. If a large nodule was present, multiple measurements for different regions were done.

\section{Ultrasound-guided fine-needle aspiration and cytological examination (FNAC)}

The suspicious nodules were localized and aspirated under US image using a 20-22G needle after sterilization without local anesthesia. At least five slides were obtained for the cytological analysis. The samples were immediately smeared and fixed in $95 \%$ ethanol. The slides were stained, examined, and analyzed by an expert cytopathologist using the six-tiered diagnostic Bethesda system [11].

Thyroid surgery was tailored and performed according to the cytological and clinical diagnoses. It was performed in only 72 cases, who had suspicious nodules (Bethesd a 4 E 5), had benign nodules (Bethesda 2) but causing compressive or clinical symptoms, or those who had cytological results of undetermined significance (Bethesda 3).

Table 3 Showing correlation between SWE and the pathological results of the nodules

\begin{tabular}{lllll}
\hline Histopathology & $E_{\text {mean }}(\mathbf{k P a})$ & Minimum $E_{\text {mean }}(\mathbf{k P a})$ & $\begin{array}{l}\text { Maximum } \\
\boldsymbol{E}_{\text {mean }}(\mathbf{k P a})\end{array}$ & \multicolumn{1}{c}{ Number } \\
\hline Benign & $24.5 \pm 12.1$ & 9.1 & 58 & 66 \\
Malignant & $69.4 \pm 27.02$ & 22 & 123 & 33 \\
Total & $39.5 \pm 28.09$ & 9.1 & 123 & 99 \\
\hline
\end{tabular}


Table 4 Showing diagnostic performance of SWE parameters

\begin{tabular}{|c|c|c|c|c|c|}
\hline $\begin{array}{l}\text { Elasticity } \\
\text { indices } \\
(\mathrm{kPa})\end{array}$ & $\begin{array}{l}\text { AUC\% } \\
(95 \% \\
\text { Cl) } \\
\end{array}$ & $\begin{array}{l}p \\
\text { value }\end{array}$ & $\begin{array}{l}\text { Cutoff } \\
\text { values } \\
(\mathrm{kPa})\end{array}$ & $\begin{array}{l}\text { Sensitivity } \\
\text { (\%) }\end{array}$ & $\begin{array}{l}\text { Specificity } \\
\text { (\%) }\end{array}$ \\
\hline$E_{\text {mean }}$ & $\begin{array}{l}93.2 \\
(88.2- \\
98.2)\end{array}$ & $\begin{array}{l}< \\
0.0001\end{array}$ & 34.35 & 84.8 & 83.3 \\
\hline ER & $\begin{array}{l}96.3 \\
(93.3- \\
99.4)\end{array}$ & $\begin{array}{l}< \\
0.0001\end{array}$ & 2.65 & 90.9 & 89.4 \\
\hline
\end{tabular}

AUC area under the curve, 95\% Cl 95\% confidence interval

\section{Statistical methods and data analysis}

Data management and analysis were performed using a statistical package for Social Sciences (SPSS) version 25 for Windows [12].

The numerical data were statistically presented in terms of median, range, or mean, and standard deviation. Categorical data were summarized as numbers and percentages. A comparison between numerical variables was done by Student's unpaired $t$ test or Mann-Whitney $U$ test for parametric data. Comparing categorical variables was done by Chi-square test or Fisher exact test.

The diagnostic performance of SWE elasticity indices (EIs) and TI-RADS scores was assessed by analyzing receiver operating characteristic (ROC) curves for predicting malignancy, optimal SWE cutoff values, and TIRADS scores. The $p$ value was considered significant when $p$ values are less than 0.05 .

\section{Results}

The obtained results could be binned into six items as follows:

\section{Analysis of conventional ultrasound and color Doppler characteristics of the nodules (Table 1)}

We had found no significant correlation between the size, number, or site of the nodules and the possibility of malignancy ( $p$ value $>0.05$ ).

We found that hypo or marked hypoechogenicity was the most significant single B-mode ultrasound criterion for malignancy; however, TI-RADS had a higher sensitivity in the detection of malignancy than the single US criterion alone.

Table 5 Showing cytological results of the nodules according to Bethesda classification

\begin{tabular}{lll}
\hline Bethesda category & Frequency & Valid percent \\
\hline 2 & 47 & 47.5 \\
3 & 4 & 4.0 \\
4 & 18 & 18.2 \\
5 & 28 & 28.3 \\
6 & 2 & 2.0 \\
Total & 99 & 100 \\
\hline
\end{tabular}

Table 6 Showing the pathological results after FNAC \pm surgery

\begin{tabular}{lll}
\hline Pathology & Frequency & Valid percent \\
\hline Benign & 66 & 66.7 \\
Malignant & 33 & 33.3 \\
Total & 99 & 100 \\
\hline
\end{tabular}

Color Doppler had shown an important role in the detection of malignancy, where the presence of intranodular vascularity (type 1b) (Table 1) was more specific to malignant nodules but its absence cannot exclude malignancy (Figs. 5 and 6).

Shear wave elastography of the nodules (Tables 2, 3, and 4) We had detected that E mean and ER of SWE were significantly higher in malignant nodules than in benign nodules $(p<0.001)$. As compared with the other SWE parameters, ER with the optimal cutoff value set at 2.6 had the highest AUC value (96.3\%; 95\% CI 93.3-99.4\%), showing a diagnostic sensitivity and specificity of 90.9 and $89.4 \%$, respectively.

\section{Cytological \pm histopathological analysis of the nodules} (Table 5, 6, and 7) (Fig. 1 a and b)

From the combined results of FNAC and surgery, we had 66 benign nodules (Figs. 2 and Fig. 3) consisting of 41 nodules of benign nodular goiter, 10 nodules of chronic lymphocytic thyroiditis (Fig. 4), and 15 nodules of follicular adenoma. Alternatively, there were 33 malignant nodules, consisting of 24 nodules of papillary carcinoma (Figs. 5 and 6), five nodules of follicular carcinoma, three nodules of medullary carcinoma (Fig. 7), and only one nodule that was anaplastic undifferentiated carcinoma.

\section{The malignancy rate and TI-RADS scores in the nodules (Table 8)}

Based on our statistics, it has been shown that the malignancy rate and the TI-RADS scores are in a positive

Table 7 Showing the histopathological types of the nodules

\begin{tabular}{lll}
\hline Surgery & Frequency & Valid percent \\
\hline Benign nodular goiter & 14 & 14.1 \\
Chronic lymphocytic thyroiditis & 10 & 10.1 \\
Follicular adenoma & 15 & 15.2 \\
Papillary carcinoma & 24 & 24.2 \\
Follicular carcinoma & 5 & 5.1 \\
Medullary carcinoma & 3 & 3.0 \\
Anaplastic carcinoma & 1 & 1.0 \\
No surgery & 27 & 27.3 \\
Total & 99 & 100 \\
\hline
\end{tabular}



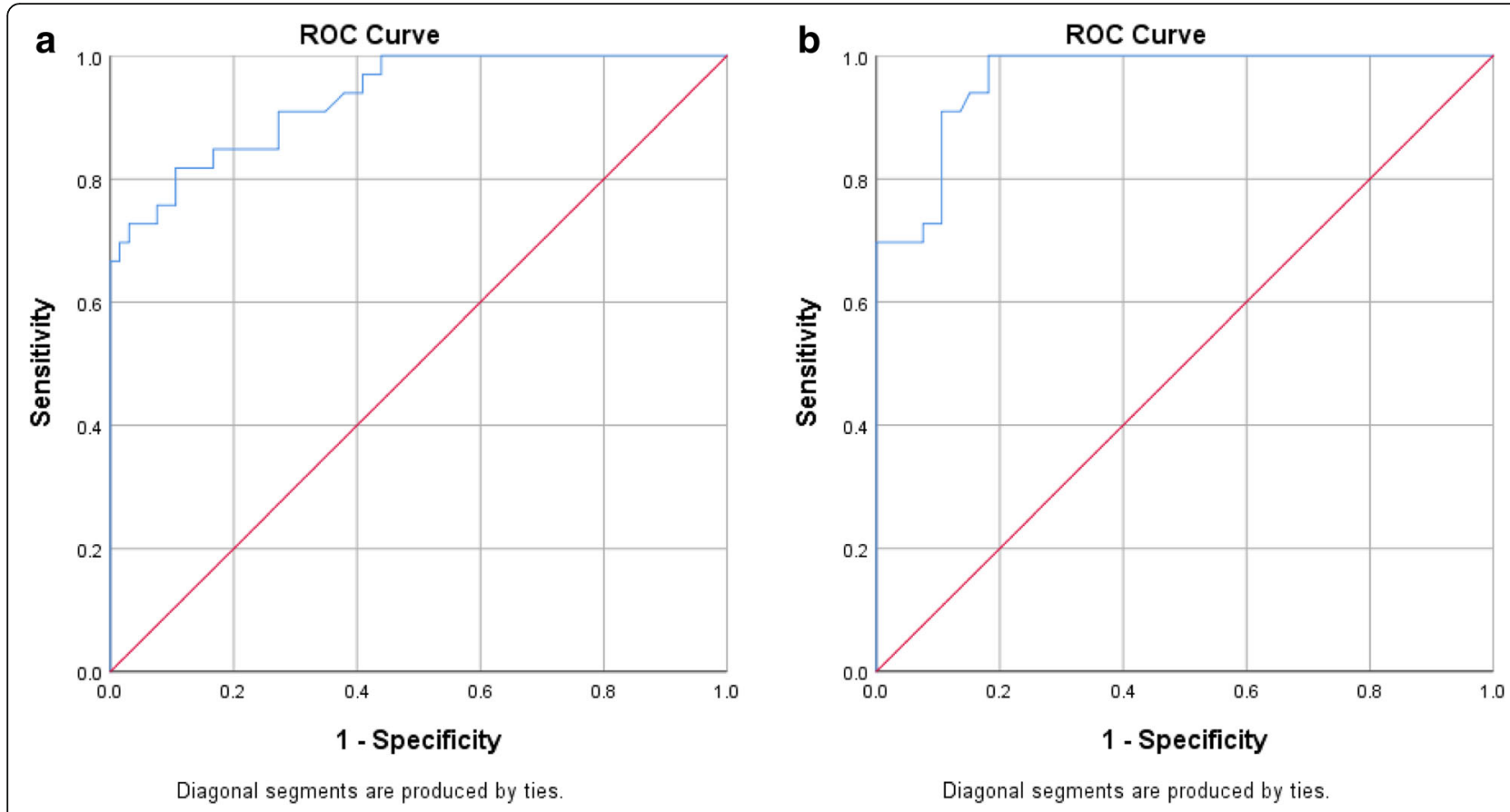

Fig. 1 a Receiver operating characteristic (ROC) curve for the $E_{\text {mean }}$ of SWE; $E_{\text {mean }}$ the mean elasticity index of the stiffest portion of the nodule. $\mathbf{b}$ Receiver operating characteristic (ROC) curve for the ER of SWE; ER the ratio of mean elasticity indices of the nodule and the parenchyma

relationship, as the malignancy rate increases with higher TI-RADS scores.

The diagnostic performance of TI-RADS, color Doppler and SWE separately and in combinations (Table 9)

In the "parallel method", when one or both methods (SWE or TI-RADS) resulted in positivity for malignancy, the results were considered positive, and only when both methods resulted in negativity were the results considered negative.

\section{Combined application of color Doppler and TI-RADS as well as SWE and TI-RADS (Table 9)}

Combined color Doppler and TI-RADS score is more significant in terms of sensitivity (87.8\%), NLR (0.145), and NPV (93.2\%), relative to sensitivity (84.8\%), NLR (0.182), and NPV (91.6\%) of the TI-RADS alone. On the whole, the "parallel method" using ER of SWE parameters and TI-RADS was more significant in terms of sensitivity (90.9\%), NLR (0.12), and NPV (94.2\%), relative to sensitivity (84.8\%), NLR (0.182), and NPV (91.6\%) of the TI-RADS alone. Finally, the "parallel" using $\mathrm{E}_{\text {mean }}$ of SWE and TI-RADS was more significant in terms of sensitivity (90.9\%), NLR (0.12), and NPV (94.2\%), which were superior to sensitivity (84.8\%), NLR (0.182), and NPV (91.6 \%) of each TI-RADS or SWE $E_{\text {mean }}$ when either used alone.

\section{Discussion}

The prevalence of thyroid nodules has necessitated the differentiation between benign and malignant ones. As the clinical examination cannot provide a definitive diagnosis, thus, ultrasonography and radioisotope scanning were employed for sorting out the nodules that should be further assessed by histopathology [9].

The sonographic appearance of suspicious nodules can predict the need for histopathological evaluation of them. The US elastography can provide an objective assessment of tissue stiffness [6].

In this context, our results had outlined the most predictive US feature of malignancy by B-mode, as hypo or marked hypo-echogenicity, with the highest sum of the sensitivity and specificity (66.6 and 90.9\%, respectively), and this was incongruent with Zhao et al. [13] who had described the micro-calcification as being the most predictive US feature of malignancy $(85 \%$ sensitivity and $75.6 \%$ specificity); this difference is explained by the different sample sizes, where they had a larger sample (313 patients) and a relatively larger number of malignant nodules (194).

From the above and in concordance with Sibos study [14], there is no single US criterion that carries sufficiently high accuracy measures in distinguishing the nodules, but the combination of multiple criteria could increase the sensitivity and specificity. 


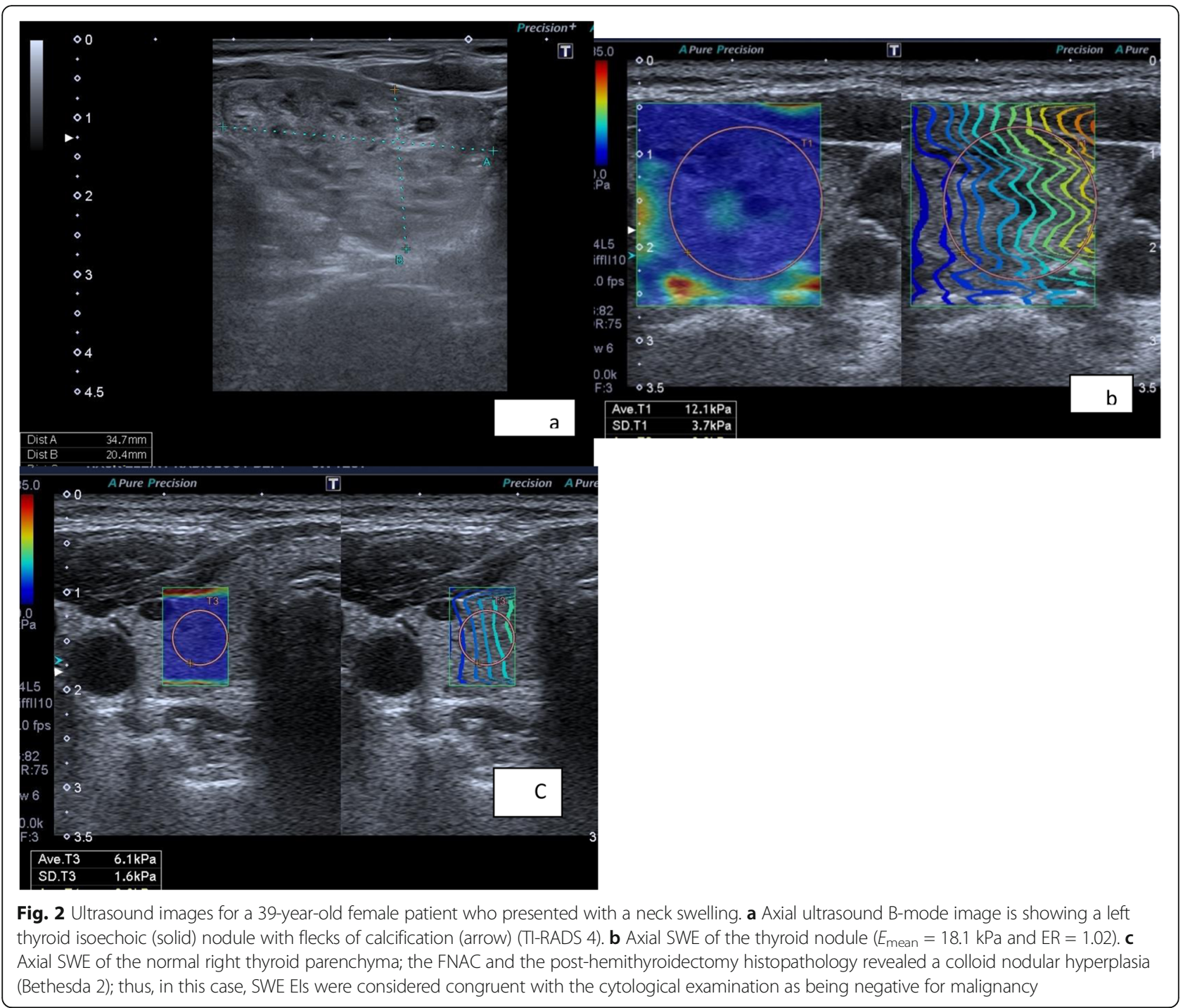

Horvath et al. [15] had introduced the TI-RADS for risk stratification of thyroid malignancy. Their tested sensitivity was $88 \%$, and NPV was $88 \%$; Russ et al. [16] had also reported high sensitivity (95.7\%) and NPV (99.7\%) for diagnosing thyroid malignancy by TI-RADS, then Tessler et al. [10] had updated the TI-RADS scoring; the latter was used in our study with the pooled sensitivity and NPV of TI-RADS (in our study) of 84.8 and $91.6 \%$, respectively.

The ROC curves-in our study-had indicated that the cutoff value of ACR TI-RADS was TR4, and the AUC was 0.84 (95\%CI 0.754-0.907) with the diagnostic sensitivity and specificity of ACR TI-RADS of $84.8 \%$ and $83.3 \%$, respectively; this was concordant with Zhang et al. [17], where their cutoff value for the ACR TIRADS was TR5, and AUC was 0.864 (95\%CI 0.879$0.934)(81.4 \%$ sensitivity and $84.8 \%$ specificity); $\mathrm{Xu}$ et al.
[18] also had reported an approximate cutoff point for malignancy by ACR TI-RADS, which was more than TR4 (80.6\% sensitivity, $78.4 \%$ specificity, and $79.6 \%$ accuracy of the average value).

By using the color Doppler, we had noticed that the presence of intra-nodular vascularity (Type 1b) was close to the possibility of malignancy, but simultaneously, the presence of the peri-nodular vascularity or avascular nodules cannot exclude it, so the color Doppler solely had a limited role in the differentiation between the thyroid nodules; however, in congruence with Manoj et al. [19], we found that (1b) pattern was the cutoff value for the suggestion of malignancy with $54.5 \%$ sensitivity, $100 \%$ specificity, and $81.4 \%$ NPV.

Shear wave elastography is one of the elastography techniques that had gained a high sensitivity and 


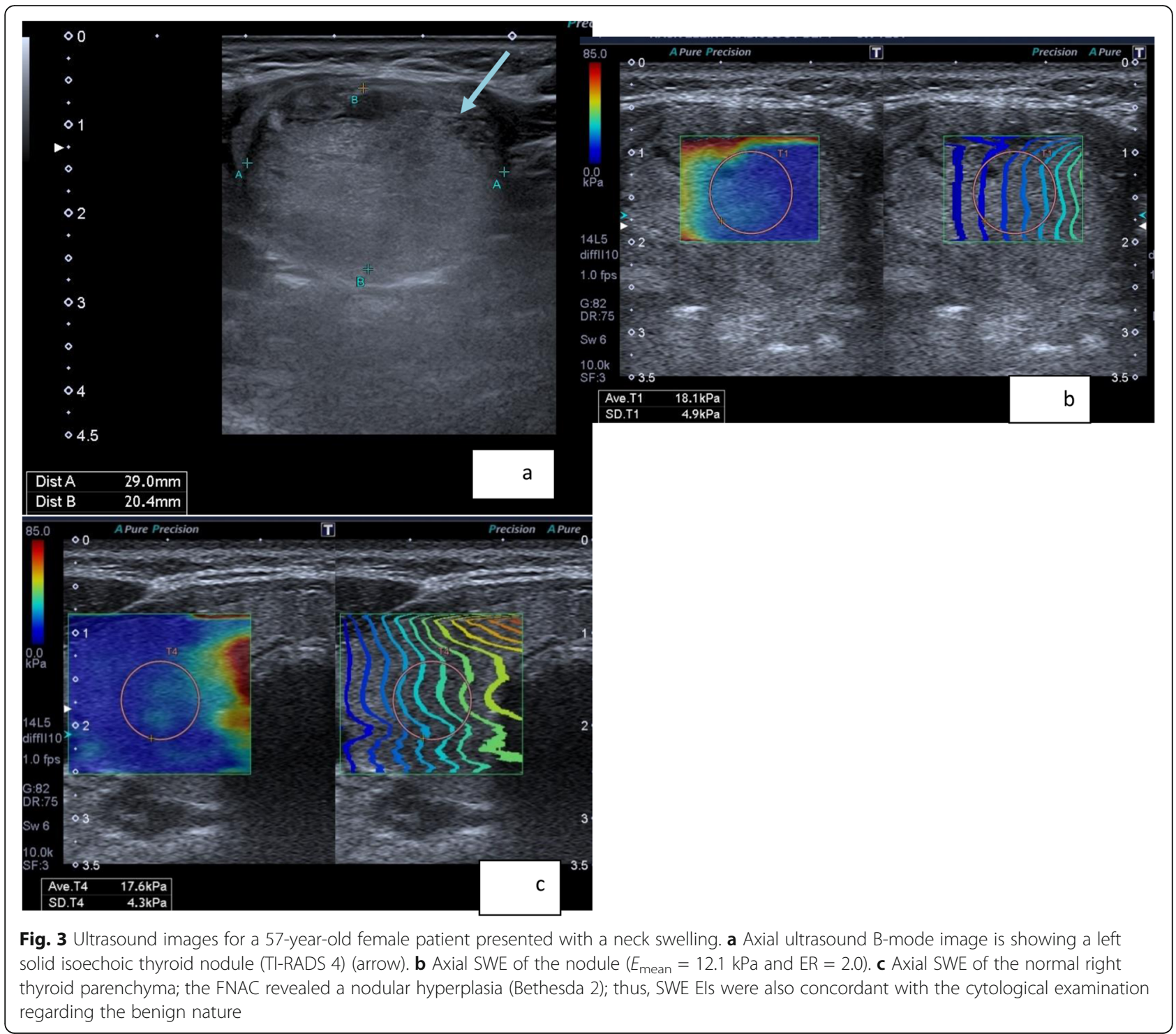

specificity for evaluation of the thyroid nodules and can decrease the unnecessary invasive procedures $[9,20]$.

We had found that EIs were significantly higher in malignant thyroid nodules than in benign ones $(p<0.0001)$, this was stated in the meta-analysis study done by Peiliang et al. (84.3\% sensitivity and $88.4 \%$ specificity) [21]

Hye et al. [22] had reported higher EIs in thyroid carcinoma relative to the benign nodules with $E_{\text {mean }}$ with diagnostic specificity of $86.4 \%$ and PLR of 4.2 ; this is nearly compatible to our study, where, the $E_{\text {mean }}$ had a diagnostic specificity of $83.3 \%$ and PLR of 5.09 .

Among the tested SWE EIs, we had selected the elasticity ratio (ER) as the best cutoff value because it has the highest sensitivity and specificity values in the differentiation between the malignant and the benign thyroid nodules. The ER cutoff value of 2.6 had the highest AUC value (96.3\%; 95\% CI 93.3-99.4\%); it had a sensitivity, specificity, PLR, PPV, and NPV of 90.9, 89.4, 8.5, 81, and $85.1 \%$, respectively.

Although matching Veyrieres et al. [23], Bhatia et al. [24], Sebag et al. [25], and Kim et al. [26] studies, up to our knowledge, the most accurate cutoff value of SWE has not yet been unified. This difference between the studies may be attributed to the choice of different standards. We had selected the best cutoff value in ER ( which was 2.6), whereas they had used the best parameter that gave a NPV or a PPV of at least $80 \%$.

Consistent with this rule in the selection of the best cut-off value, many published studies over the past years are concordant with us, including Liu et al. [27], Park et al. [28], Zhao et al. [13], and Zhang et al. [17], where 


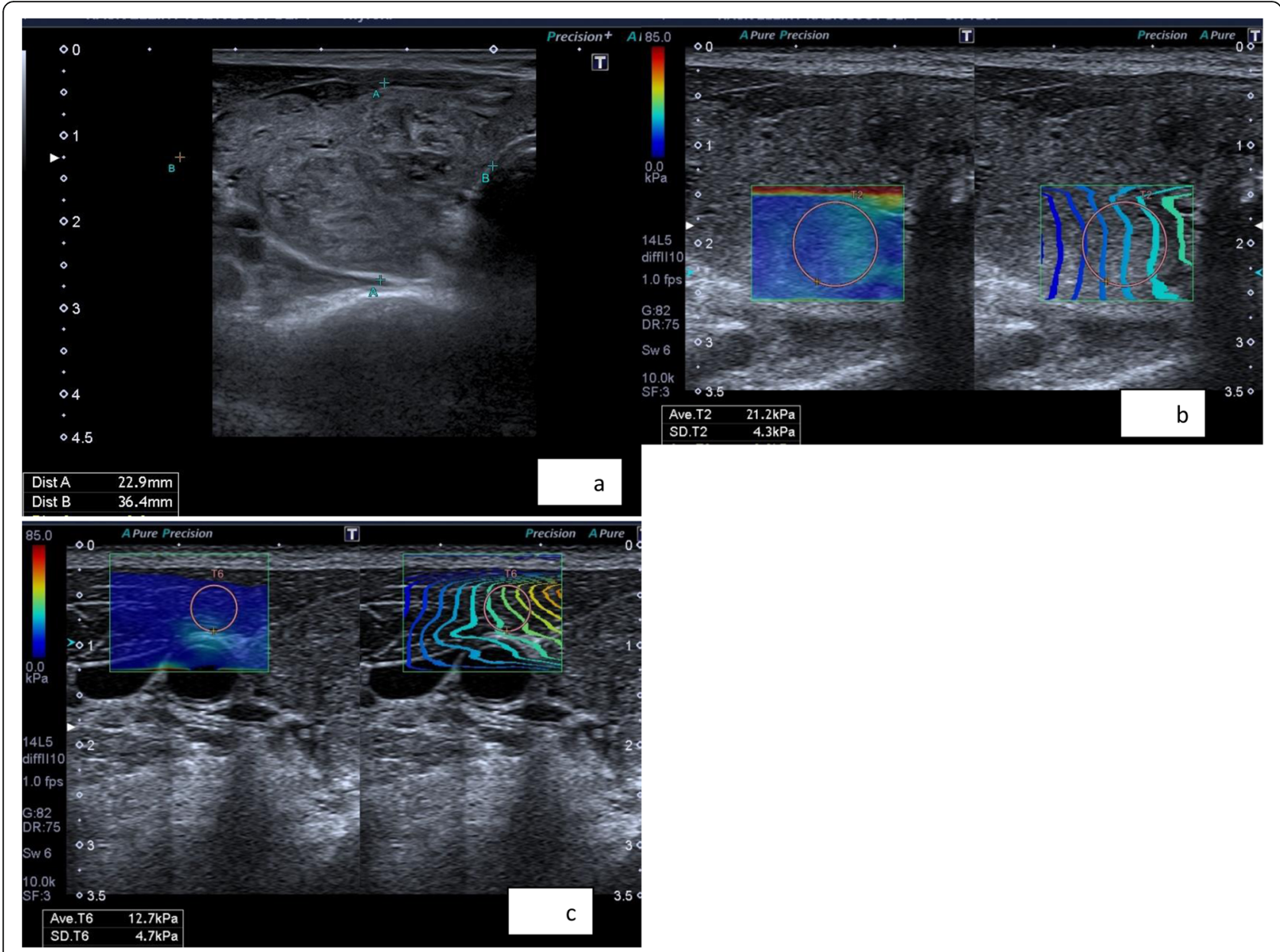

Fig. 4 Ultrasound images for a 55-year-old male patient. a Axial ultrasound B-mode image is showing a right solid heterogeneous thyroid nodule (TI-RADS 3). $\mathbf{b}$ Axial SWE of the thyroid nodule $\left(E_{\text {mean }}=21.2 \mathrm{kPa}\right.$ and $\left.E R=1.6\right)$. $\mathbf{c}$ Axial SWE of the normal right sternocleidomastoid muscle; the FNAC revealed abundant lymphocytic cells with scanty follicular cells (Bethesda 2), and the post total thyroidectomy histopathological results had confirmed the diagnosis of chronic lymphocytic thyroiditis; thus, SWE Els were matching the cytological examination

they had also considered that the EIs are significantly higher in malignant nodules with high accuracy measures.

Adding to our knowledge, two important salient findings - in our study-were demonstrated where the combination of SWE and TI-RADS as well as color Doppler and TI-RADS to a certain extent had increased the diagnostic performance in differentiating thyroid nodules. Moreover, when we used the SWE (ER) and TI-RADS, we had obtained higher accuracy measures compared with the TI-RADS alone; therefore, such a combination of TI-RADS and EIs can minimize the need for unnecessary surgery or biopsy in suspicious thyroid nodules; this was concordant with Park et al. [28], Zhao et al. [13], and $\mathrm{Xu}$ et al.'s [18] studies, where the combined use of the TI-RADS findings and the EIs had increased the accuracy measures.
However, it had been shown that the rise in the sensitivity was from $84.8 \%$ of TI-RADS alone to $90.9 \%$ with the combination of TI-RADS and SWE in "parallel" but the specificity was lower $(74.2 \%)$ as compared with TIRADS alone (83.3\%); this was explained by the statistical way in which we chose the positive cases of possible malignancy as we use the parallel method when one or both methods had resulted in positivity, and the results were considered negative when only both methods had resulted in negativity; this relationship between both methods is termed "parallel"; and it can explain why the sensitivity is higher while the specificity is lower in the combined method than in TI-RADS alone.

Finally, from our results, we had found that the SWE and TI-RADS can form a complementary relationship in terms of the advantages. Where the TI-RADS can compensate for the limitations of SWE (that may be disturbed by macro-calcifications and the carotid artery 


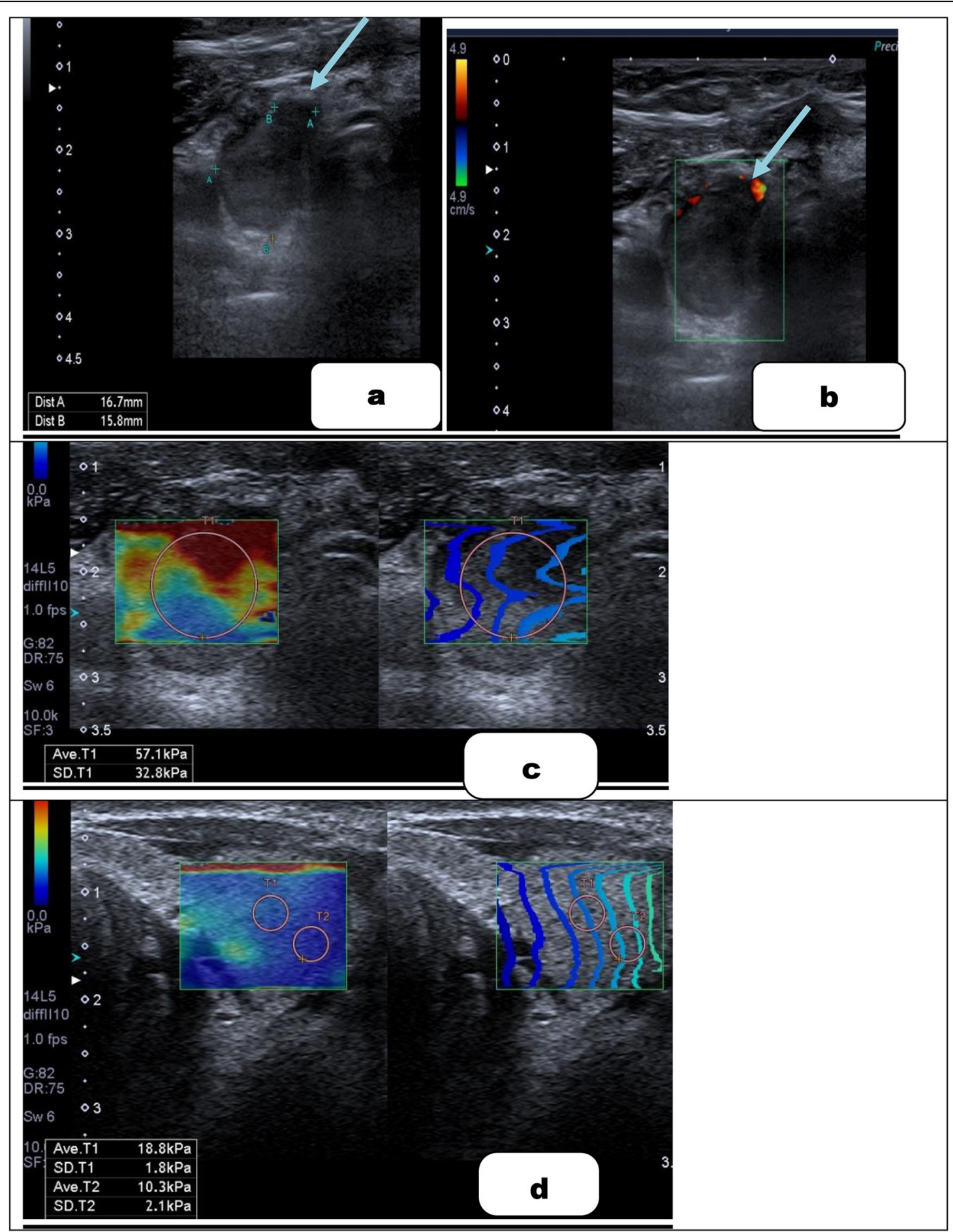

Fig. 5 Ultrasound images for a 60-year-old female patient. a Axial ultrasound B-mode image is showing a right solid hypoechoic thyroid nodule with an irregular margin and peripheral calcification (TI-RADS 5) (arrow). b Axial color image is showing peripheral vascularity (1a) (arrow). c Axial SWE of the thyroid nodule ( $E_{\text {mean }}=57.0 \mathrm{kPa}$ and $E R=3$ ). $\mathbf{d}$ Axial SWE of normal left thyroid parenchyma; the FNAC revealed malignant cells with psammoma bodies (Bethesda 5), and the post right hemithyroidectomy histopathology had confirmed the diagnosis of papillary thyroid carcinoma

pulsations) and vice versa, the SWE can compensate for TI-RADS, which can be influenced by the operator dependence and the interobserver variability. Thus, we suggest using SWE for the thyroid nodules with TIRADS score greater than or equal to 4 as a complementary tool, other than doing the diagnosis separately to 


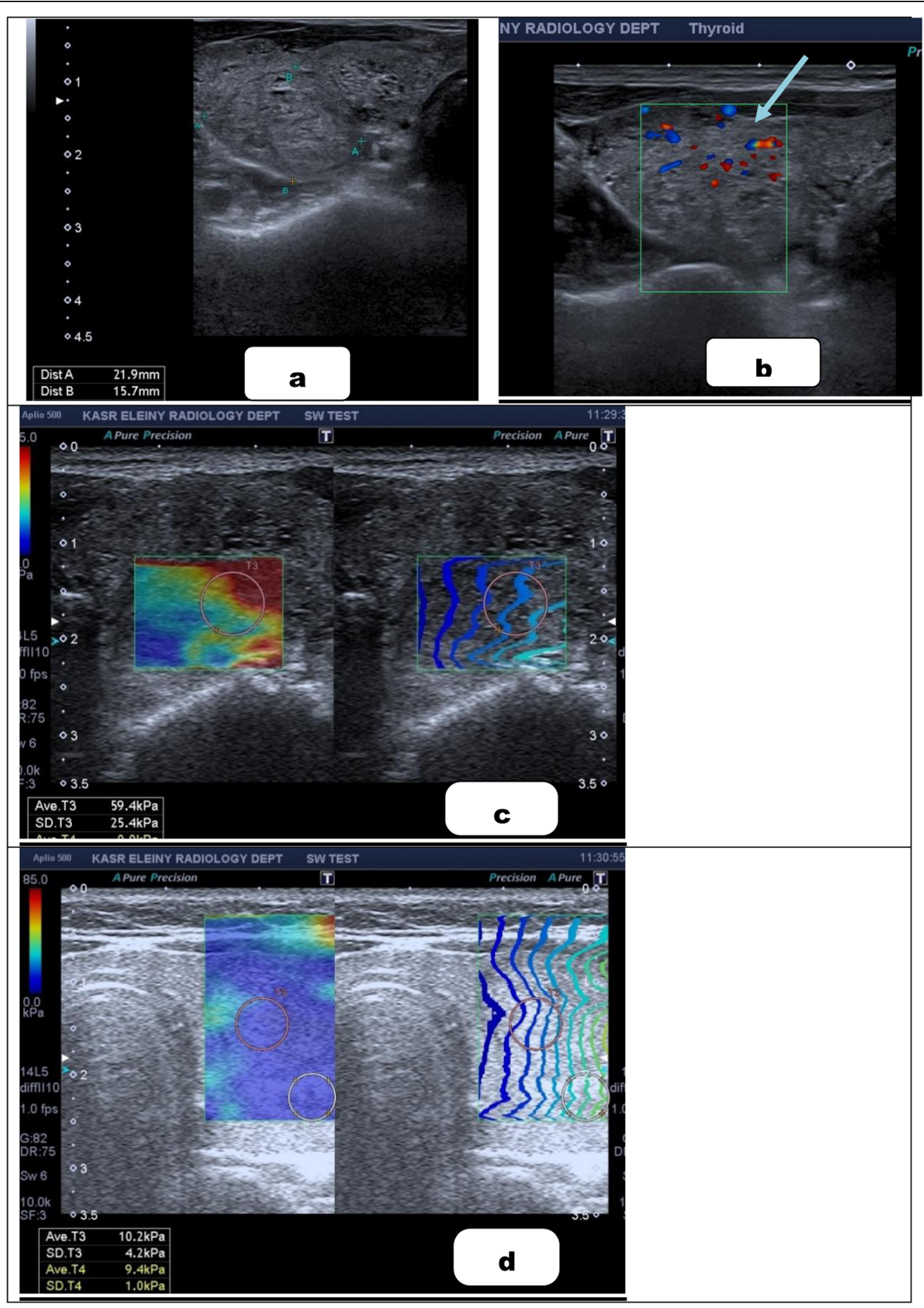

Fig. 6 Ultrasound images for a 58-year-old female patient. a Axial ultrasound B-mode image is showing two solid thyroid nodules that are isoechoic with calcification (TI-RADS 5). $\mathbf{b}$ Axial color image is showing internal vascularity (1b) (arrow). $\mathbf{c}$ Axial SWE of the thyroid nodule ( $E_{\text {mean }}=$ $59.4 \mathrm{kPa}$ and $\mathrm{ER}=5.8)$. $\mathbf{d}$ Axial SWE of the normal left thyroid parenchyma; the FNAC revealed malignant cells with psammomatous calcification (Bethesda 5), and the post right hemithyroidectomy histopathological examination had confirmed the presence of papillary thyroid carcinoma 

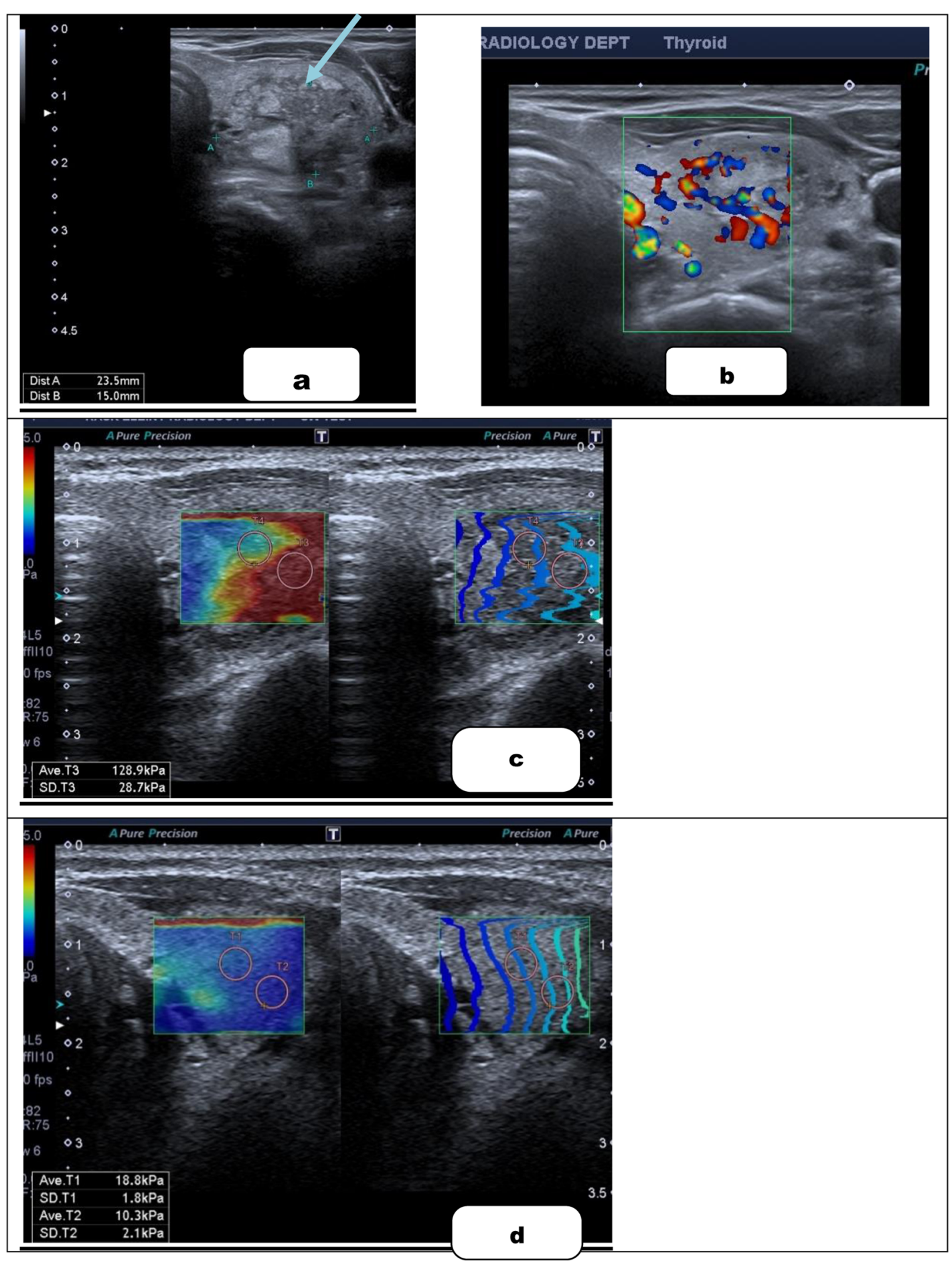

Fig. 7 Ultrasound images for a 53-year-old male patient. a Axial ultrasound B-mode image is showing heterogeneous left solid thyroid nodules that are hypo to isoechoic with punctuate and macro calcification (TI-RADS 4) (arrow). b Axial color image is showing both peripheral and internal vascularity (1c). c Axial shear wave elastography of the thyroid nodule ( $E_{\text {mean }}=128.9 \mathrm{kPa}$ and $\mathrm{ER}=6.8$ ). $\mathbf{d}$ Axial SWE of the normal right thyroid parenchyma; the FNAC revealed malignant cells with psammomatous calcification (Bethesda 5), and the post total thyroidectomy histopathological examination had confirmed the presence of medullary thyroid carcinoma 
Table 8 Showing the malignancy rate according to the TI-RADS score of the 99 nodules after FNAC \pm thyroid surgery

\begin{tabular}{lllll}
\hline TI-RADS score & No. of cases & Benign & Malignant & Malignancy rate (\%) \\
\hline 3 & 60 & 55 & 5 & 8.3 \\
4 & 37 & 11 & 26 & 70.3 \\
5 & 2 & 0 & 2 & 100 \\
Total & 99 & 66 & 33 & \\
\hline
\end{tabular}

avoid unnecessary invasive diagnostic procedures in suspicious nodules.

Some limitations had been met in this work including the following:

First, all malignant nodules (24/33) were papillary carcinomas, while only three nodules were medullary carcinomas, and most of the benign nodules were nodular goiters; thus, other pathological types were not included, such as Hurthle cell thyroid carcinoma and primary thyroid lymphoma; thus, their tested parameters were not examined in this study.

Second, it is a one-center experience, so the data need to be tested by prospective multicenter and nonspecialized members to eliminate this selection bias.

Third is the isthmic lesions, where the relatively small size of the isthmus compared with the thyroid lobes and the ROI should cover the whole nodule with sufficient surrounding parenchyma are needed; however, isthmic lesions were seen in 10 of our cases, most of them were "isthmi-lobar" in location, thus surrounding thyroid parenchyma served to avoid this limitation; however, in pure isthmic lesions, breath-holding and cessation of swallowing as well as the application of a copious amount of gel is considered of paramount importance, moreover, repeating the process, where at least 3 successive measurements were taken for each nodule to choose the best SWE image.

Forth, is the interlintra-observer variability and the operator dependency, this was much lessened by conducting the examinations using the same US machine at the same setting of the conventional US examination, and by the same operator under the direct supervision of an experienced senior.

Last, selection bias may exist because patients included in our study were scheduled for US-guided FNAC for suspicious thyroid nodules with US features $(\mathrm{TR} \geq 3)$, this may decrease the diagnostic performance on TIRADS, causing false-negative cytologic results.

Finally, it would be interesting to see any solid and conclusive results that can lead to a change in practice as the researches about the SWE are there and giving promising results for a long time, but it is not included in any known thyroid scoring systems so far.

Table 9 Showing a comparison of diagnostic performance of TI-RADS alone, SWE alone, color Doppler alone, and the combined parallel method

\begin{tabular}{|c|c|c|c|c|c|c|c|c|c|c|}
\hline Imaging method & & Malignant & Benign & AUC\% & Sensitivity & Specificity & PLR & NLR & PPV & NPV \\
\hline \multirow[t]{2}{*}{ TI-RADS alone (4 as a cutoff value) } & + & 28 & 11 & $84(75.4-90.7)$ & 84.8 & 83.3 & 5.09 & 0.182 & 71.7 & 91.6 \\
\hline & - & 5 & 55 & & & & & & & \\
\hline \multirow[t]{2}{*}{ Color Doppler alone (1b as a cutoff value) } & + & 18 & 0 & $77(67.8-85.1)$ & 54.5 & 100 & & 0.45 & 100 & 81.4 \\
\hline & - & 15 & 66 & & & & & & & \\
\hline \multirow[t]{2}{*}{ SWE alone (ER 2.6 as a cutoff value) } & + & 30 & 7 & $96(93.3-99.4)$ & 90.9 & 89.3 & 8.5 & 0.10 & 81.08 & 95.1 \\
\hline & - & 3 & 59 & & & & & & & \\
\hline \multirow[t]{2}{*}{ SWE alone ( $E_{\text {mean }} 34.3$ as cutoff value) } & + & 28 & 11 & $84(75.4-90.7)$ & 84.8 & 83.3 & 5.09 & 0.182 & 71.7 & 91.6 \\
\hline & - & 5 & 55 & & & & & & & \\
\hline \multirow[t]{2}{*}{ Combined TIRADS \& color Doppler } & & 29 & 11 & $85(77.1-91.9)$ & 87.8 & 83.3 & 5.2 & 0.145 & 72.5 & 93.2 \\
\hline & & 4 & 55 & & & & & & & \\
\hline \multirow[t]{2}{*}{ Combined TIRADS + SWE (ER) } & + & 30 & 17 & $\#$ & 90.9 & 74.2 & 3.5 & 0.12 & 63.8 & 94.2 \\
\hline & - & 3 & 49 & & & & & & & \\
\hline \multirow[t]{2}{*}{ Combined TIRADS + SWE ( $\left.E_{\text {mean }}\right)$} & + & 30 & 21 & $\#$ & 90.9 & 68.1 & 2.8 & 0.133 & 58.8 & 93.7 \\
\hline & - & 3 & 45 & & & & & & & \\
\hline
\end{tabular}

AUC, areas under the ROC curve; $P L R$, positive likelihood ratio; $N L R$, negative likelihood ratio; $P P V$, positive predictive value; $N P V$, negative predictive value; $95 \%$ l, 95\% confidence interval

+ stands for positivity for malignancy, - stands for negativity for malignancy, \# stands for not applicable 


\section{Conclusion}

Elasticity indices had shown a significantly high diagnostic value that is comparable to the histopathological results. Combined SWE, color Doppler, and TI-RADS could effectively complement each other in the differentiation between the thyroid nodules as a sum of findings. Furthermore, the combined method could be used as a simple and non-invasive tool that accurately stratifies the risk of malignancy and surrogates the invasive diagnostic procedures.

\section{Abbreviations}

Els: Elasticity indices; $E_{\text {mean }}$ : The mean elasticity index of the stiffest portion of the nodule; ER: The ratio of mean elasticity index of the lesion and the normal parenchyma or subjacent sternocleidomastoid muscle; FNAC: Fineneedle aspiration cytology; SWE: Shear wave elastography; TI-RADS: Thyroid imaging reporting and data system

\section{Acknowledgments}

Not applicable

\section{Authors' contributions}

$A A B$, the corresponding author, had contributed by supervising the ultrasound examinations and in the final editing and submission of the manuscript. AHMA had done the ultrasound examinations for the patients and shared in the manuscript editing and reference collection. YFG had reported the histopathology findings for the sampled cases. KHE had introduced the idea of the current study and helped in the image selection and revised the final version of the submitted manuscript. The authors have read and approved the manuscript.

\section{Funding}

All authors had no fund for this research and had no competing interests.

\section{Availability of data and materials}

All data are available on a software system owned by each of the authors, and the corresponding author has the authority to respond if there is any query.

\section{Declarations}

\section{Ethics approval and consent to participate}

The protocol was reviewed and approved by the local ethics committee of the radiology department, Kasr Alainy Hospital, Cairo University (reference number: Code D-24-2019, Date of approval 13-07-2019). All patients had given their written consents to participate in this work.

\section{Consent for publication}

All patients had given their written consents for publication of this work.

\section{Competing interests}

All authors have no competing interests.

\section{Author details \\ ${ }^{1}$ Radiology Department, Faculty of Medicine, Cairo University, Cairo, Egypt.}

${ }^{2}$ Radiology Departement, Faculty of Medicine, Cairo University, Cairo, Egypt.

\section{Received: 23 January 2021 Accepted: 23 March 2021}

\section{Published online: 13 April 2021}

\section{References}

1. Mcnicol A (2007) Pathology of thyroid tumors. Surg Oxford 25(11):458-462

2. Hegedüs L, Steen JB et al (2003) Management of simple nodular goiter: current status and future perspectives. Endocrine Rev 24(1):102-132. https:// doi.org/10.1210/er.2002-0016

3. Frates MC, Benson CB, Charboneau JW, Cibas ES, Clark OH, Coleman BG, Cronan JJ, Doubilet PM, Evans DB, Goellner JR, Hay ID, Hertzberg BS, Intenzo CM, Jeffrey RB, Langer JE, Larsen PR, Mandel SJ, Middleton WD, Reading CC,
Sherman SI, Tessler FN, Society of Radiologists in Ultrasound (2005) Management of thyroid nodules detected at US: Society of Radiologists in Ultrasound consensus conference statement. Radiology 237(3):794-800. https://doi.org/10.1148/radiol.2373050220

4. Wynford-Thomas D (1993) Molecular genetics of thyroid cancer. Trends Endocrinol Metab 4(7):224-232. https://doi.org/10.1016/1043-2760(93)90126-Y

5. Kwak JY, Kim EK (2014) Ultrasound elastography for thyroid nodules: recent advances. Ultrasonography 33(2):75-82. https://doi.org/10.14366/usg.13025

6. Cantisani V, Lodise P, Grazhdani H, Mancuso E, Maggini E, di Rocco G, D'Ambrosio F, Calliada F, Redler A, Ricci P, Catalano C (2014) Ultrasound elastography in the evaluation of thyroid pathology. Current status. Eur J Radiol 83(3):420-428. https://doi.org/10.1016/j.ejrad.2013.05.008

7. Abdel Razek AA (2010) Diffusion-weighted magnetic resonance imaging of head and neck. J Comput Assist Tomogr 34(6):808-815

8. Shokry A, Hassan T, Baz A et al (2018) Role of diffusion-weighted magnetic resonance imaging in the differentiation of benign and malignant thyroid nodules. Egypt J Radiol Nuclear Med 49(4):1014-1021. https://doi.org/10.101 6/j.ejrnm.2018.06.013

9. Nell S, Kist JW, Debray TP et al (2015) Qualitative elastography can replace thyroid nodule fine-needle aspiration in patients with soft thyroid nodules. A systematic review and meta-analysis. Eur J Radiol. 84(4):652-661. https:// doi.org/10.1016/j.ejrad.2015.01.003

10. Tessler F, Middleton W, Grant E et al (2017) ACR Thyroid Imaging, Reporting and Data System (TI-RADS): white paper of the ACR TI-RADS committee. J Am Coll Radiol 14(5):587-595. https://doi.org/10.1016/j.jacr.2017.01.046

11. Cibas ES, Ali SZ (2007) The Bethesda system for reporting cytopathology. Thyroid. 19(11):1159-1165

12. Galen RS (1980) Predictive values and efficiency of laboratory testing. Pediat J Clin North Am 27(4):861-869. https://doi.org/10.1016/S0031-3 955(16)33930-X

13. Zhao L, Hui J, Xue $\mathrm{H}$ et al (2017) Shear wave elastography combined with the thyroid imaging reporting and data system for malignancy risk stratification in thyroid nodules. Oncotarget journal. January. 8(26): 43406-43416

14. Sipos JA (2009) Advances in ultrasound for the diagnosis and management of thyroid cancer. Thyroid (19):1363-1372

15. Horvath E, Majlis S, Rossi R et al (2009) An ultrasonogram reporting system for thyroid nodules stratifying cancer risk for clinical management. J Clin Endocrinol Metab (94):1748-1751

16. Russ G, Royer B, Bigorgne C, Rouxel A, Bienvenu-Perrard M, Leenhardt L (2013) Prospective evaluation of thyroid imaging reporting and data system on 4550 nodules with and without elastography. Eur J Endocrinol 168(5): 649-655. https://doi.org/10.1530/EJE-12-0936

17. Zhang W-B, Li JJ et al (2020) SWE combined with ACR TI-RADS categories for malignancy risk stratification of thyroid nodules with indeterminate FNA cytology, pp 1-10

18. Xu X, He X, Guo L et al (2019) The diagnostic value of the maximum value of Young's modulus of shear-wave elastography and ACR TI-RADS for thyroid nodules. J Clin Otorhinolaryngol. 33(8):764-767

19. Manoj KP, Senthil KA, Upasana R et al (2016) Role of gray scale, color Doppler, and spectral Doppler in differentiation between malignant and benign thyroid nodules. J Clin Diagnosis Res 10(8):01-06

20. Binglan Z, Xuelei M, Nana W et al (2013) Shear wave elastography for differentiation of benign and malignant thyroid nodules: a meta-analysis. $J$ Ultrasound Med (32):2163-2169

21. Peiliang L, Chen M, Liu B et al (2014) Diagnostic performance of shear wave elastography in the identification of malignant thyroid nodules: a metaanalysis. EurRadiol 24:2729-2738

22. Hye JK, Mi KK, In HC et al (2019) Utility of shear wave elastography to detect papillary thyroid carcinoma in thyroid nodules: efficacy of the standard deviation elasticity. Korean J Intern Med. 34(4):850-857

23. Veyrieres JB, Albarel F, Lombard JV et al (2012) A threshold value in shear wave elastography to rule out malignant thyroid nodules: A reality? Eur J Radiol (81):3965-3972

24. Bhatia K, Tong CS, Cho CC, Yuen EH, Lee J, Ahuja AT (2012) Reliability of shear wave ultrasound elastography for neck lesions identified in routine clinical practice. Ultraschall Med 33(5):463-468. https://doi.org/10.1055/s0032-1325330

25. Sebag J, Vaillant-Lombard BJ et al (2010) Shear wave elastography: a new ultrasound imaging mode for the differential diagnosis of benign and 
malignant thyroid nodules. J Clin Endocrinol Metab 95(12):5281-5288. https://doi.org/10.1210/jc.2010-0766

26. Kim H, Kim JA, Son EJ et al (2013) Quantitative assessment of shear-wave ultrasound elastography in thyroid nodules: diagnostic performance for predicting malignancy. EurRadiol (23):2532-2537

27. Liu BX, Xie XY, Liang JY, Zheng YL, Huang GL, Zhou LY, Wang Z, Xu M, Lu MD (2014) Shear wave elastography versus real-time elastography on evaluation thyroid nodules: a preliminary study. Eur J Radiol 83(7):11351143. https://doi.org/10.1016/j.ejrad.2014.02.024

28. Park AY, Son EJ, Han K, Youk JH, Kim JA, Park CS (2015) Shear wave elastography of thyroid nodules for the prediction of malignancy in a large scale study. Eur J Radiol. Mar 84(3):407-412. https://doi.org/10.1016/j.ejrad.2 014.11 .019

\section{Publisher's Note}

Springer Nature remains neutral with regard to jurisdictional claims in published maps and institutional affiliations.

\section{Submit your manuscript to a SpringerOpen ${ }^{\circ}$ journal and benefit from:}

- Convenient online submission

- Rigorous peer review

- Open access: articles freely available online

High visibility within the field

- Retaining the copyright to your article

Submit your next manuscript at $\boldsymbol{\nabla}$ springeropen.com 